\title{
CHRONIC POLYARTHRITIS AFTER CHIKUNGUNYA FEVER
}

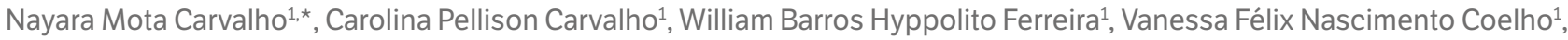
Maria Veronica Russo Macchi ${ }^{1}$, André Marun Lyrio ${ }^{1}$, Rubens Bonfiglioli ${ }^{1}$, Jose Alexandre Mendonça ${ }^{1}$, Lucas Eduardo Pedri ${ }^{1}$, Flávia Regina Andrade ${ }^{1}$, Fernanda Bertucci Sanches ${ }^{1}$, Claudia Valeria Vierhout ${ }^{1}$, Marina De Souza Vieira ${ }^{1}$

1.Pontifícia Universidade Católica de Campinas, Campinas (SP), Brazil.

${ }^{\star}$ Corresponding author: naym.carv@gmail.com

\section{BACKGROUND}

Chikungunya fever is an arbovirosis, transmitted by the Aedes aegypti. It can affect people of all ages and is characterized by the occurrence of intense and debilitant polyarthralgia, which may advance to a chronic picture.

\section{CASE REPORT}

Male patient, 57 years old, from Campinas (SP), referred that in May 2021, after a trip to the Sorocaba (SP) region, he began having fever, myalgia, associated with symmetric inflammatory arthralgia in hands and wrists joints. Performed serology for chikungunya, with positive IgM. Evolved with chronic inflammatory polyarthralgia of the same joints and of the knees. Performed articular ultrasound with diffuse synovitis signs in metacarpophalangeal, with positive power Doppler-methotrexate being introduced.

\section{CONCLUSION}

After arboviral infections, especially in chikungunya, patients may evolve with chronic polyarthritis, similar to rheumatoid arthritis, including disease modifying antirheumatic drugs for treatment.

\section{KEYWORDS}

Chikungunya, Polyarthritis, Fever. 